I believe that such an approach will call for considerable changes in medical education before we are far into the twentyfirst century. It is time already that the old-fashioned academic ideas of the sort of education needed in common for all doctors should be scrapped. I have given a list earlier of the different levels of human biology, and I believe that an honest education in depth in any one of them would provide the necessary background for the whole life process of education which is the essence of a real profession. In my undergraduate days I was taught nothing about the experimental virology and immunology that was to be my life's work, but, in one way or another, from Orme Masson, W. A. Osborne, R. R. Stawell, and a few others, I did obtain an education in depth that allowed me to build up my own picture of man as the current edge of the evolutionary process-no more and no less-which has been behind everything worth-while that I have done or written. For everyone two things can come from a good educationthe ability to handle ideas and situations and a sense of the things that are important. At the present time I believe that the current prestige of academic laboratory research, especially in molecular biology, is inducing a sense of values which is quite unsuited for more than a tiny fraction of medical graduates. I hope to see a new approach which will allow each initiate to medicine to choose his own area of intensive study -and especially to allow those who, from their interest in human beings rather than in ideas, will be the best doctors to concentrate on the behavioural sciences rather than on the laboratory ones.
In Table II I have made a suggestion as to the sort of approach to tertiary education for medicine that I believe will have to emerge during the next 40 or 50 years. There is no

\begin{tabular}{|c|c|c|c|c|c|c|}
\hline \multirow{2}{*}{\multicolumn{3}{|c|}{ Human Biology }} & \multirow{3}{*}{$\begin{array}{c}\begin{array}{c}\text { Doctors } \\
\text { of First } \\
\text { Contact }\end{array} \\
\begin{array}{c}+ \\
+ \\
+ \\
+ \\
+ \\
+\end{array}\end{array}$} & \multicolumn{3}{|c|}{ Hospital Personnel } \\
\hline & & & & \multirow{2}{*}{$\begin{array}{c}\begin{array}{c}\text { Adminis- } \\
\text { trator }\end{array} \\
+++ \\
++ \\
+ \\
+ \\
+\end{array}$} & \multirow{2}{*}{ 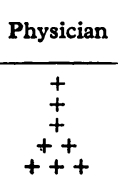 } & \multirow{2}{*}{$\begin{array}{c}\text { Specialist } \\
\stackrel{+}{+} \\
+\stackrel{+}{+}+ \\
+\end{array}$} \\
\hline $\begin{array}{l}\text { 1. Species } \\
\text { 2. Individual } \\
\text { 3. Functional anatomy } \\
\text { 4. Cellular dynamics } \\
\text { 5. Molecular biology }\end{array}$ & $\begin{array}{l}\ldots \\
\cdots \\
\cdots\end{array}$ & $\begin{array}{l}\ldots \\
\because \\
\because \\
.\end{array}$ & & & & \\
\hline
\end{tabular}

detail whatever in it, but it contains everything that I should like to leave with you from this talk:

1. That medicine must become progressively more diverse, but that it must always be firmly based on human biology.

2. That education in depth is practicable only in an area that directly interests the student ; but that, with modern knowledge and techniques of communication, perfectly adequate performance can be obtained, even in professional fields, after quite superficial education.

3. That, for large groups within the profession and especially for the doctor of first contact, education in depth will be or should be concentrated on the behavioural sciences, the sciences that deal with the individual as a whole.

\title{
Medical Investigation of Retinal Vascular Occlusion
}

\author{
C. J. ELLIS*; D. B. HAMER*; R. W. HUNT*; A. F. LEVER, † M.B., B.SC., M.R.C.P. ; R. S. LEVER*; \\ W. S. PEART, M.D., F.R.C.P. ; S. M. WALKER*
}

Brit. med. F., 1964, 2, 1093-1098

The present paper reports the medical investigation and followup of 146 patients with occlusion of retinal vessels (106 venous, 40 arterial). In most of the more recent reports of the condition (Jensen, 1936; Braendstrup, 1950; Duff, Falls, and Linman, 1951 ; Cassady, 1953 ; Klien, 1953 ; Anderson and Vallotton, 1955 ; Stephenson, 1956 ; Wise, 1957 ; Law, 1957 ; Tiburtius, 1960 ; Vannas and Tarkkanen, 1960 ; Thorne, 1961) the emphasis has been on the ophthalmic rather than the associated medical features. Liversedge and Smith (1962), however, reported the medical investigation of 63 cases of retinal artery occlusion.

\section{Clinical Material and Methods}

During 1961-3 146 patients with retinal vascular occlusion were seen in the medical clinic at the Western Ophthalmic Hospital. All cases were referred by an ophthalmologist, by whom the diagnosis had usually been made. For the most part patients were not referred on account of medical complications.

Cases with diabetic or hypertensive retinopathy or with macular degeneration were not included in the present series unless associated with a definite vascular occlusion. A small number of cases with Eales's disease or periphlebitis retinae were also excluded.

* Medical Student, Medical Unit, St. Mary's Hospital, London. t Lecturer in Medicine, Medical Unit, St. Mary's Hospital, London. $\$$ Professor of Medicine, Medical Unit, St. Mary's Hospital, London.
During 1963, where possible, all patients were asked about their smoking habits. These were divided into the six categories shown in Table I. Patients smoking both pipe and cigarettes were arbitrarily placed in the appropriate cigarettesmoking group. A history of smoking habits was obtained in 133 of the 146 cases.

\begin{tabular}{l|r|r|r|r|r|r|r}
\hline \multicolumn{10}{c|}{ TABLE I } \\
\hline
\end{tabular}

\section{Control Groups}

During 1963 the age, occupation, smoking habits, ophthalmic condition, and blood-pressure of 338 unselected ophthalmic patients were recorded. This control series was similar to the 
retinal vascular occlusion group in its social class distribution. In no patient was a retinal vascular occlusion present. Cases were allocated from this group to each of three smaller groups.

Blood-pressure Control Group.-By a process of random allocation, each case of retinal vascular occlusion was matched with one control case of the same sex and age (decade). The distribution of blood-pressure was compared in the two groups.

Smoking Control Group.-Ninety-seven control cases were matched in a similar manner with the 97 cases of retinal venous occlusion from whom a history of smoking habits had been obtained (Table I). In the same way 28 control cases were matched with 28 cases of arterial occlusion. These two control groups form the basis of a comparison with the smoking habits of patients with retinal venous and arterial occlusion.

Carcinoma Control Group.-During the period of this study 378 patients with conditions other than retinal vascular occlusion were seen in the medical clinic. After randomization 146 of these cases were individually matched with the 146 cases of retinal vascular occlusion for age (decade) and sex. No patient in either group was referred to the clinic on account of diagnosed or suspected carcinoma. Both groups were followed by the same clinicians for a comparable period. The incidence of carcinoma in the two groups has been compared.

\section{Glucose-tolerance Test}

A glucose-tolerance test was regarded as of diabetic type if the blood sugar remained above $120 \mathrm{mg}$. $/ 100 \mathrm{ml}$. two hours after $50 \mathrm{~g}$. of glucose by mouth.

\section{Ophthalmic Features of Retinal Vascular Occlusion}

The ophthalmic features of the four types of occlusion are considered separately.

\section{Occlusion of Central Retinal Vein}

An occlusion of the central retinal vein was present in 56 patients (right eye 25 , left eye 28 , bilateral 3 ). One patient (Case 11) had a left segmental venous occlusion two years after right central venous occlusion. The onset of the condition was usually sudden, with unilateral loss of vision occurring over the course of several minutes. The characteristic early changes seen in the fundus were gross venous distension and widespread retinal haemorrhage, together with some degree of disk-swelling.

Glaucoma developed in 12 patients. In one of these it led to an enucleation of the eye. In one further case a central venous occlusion occurred in a patient with bilateral simple open angle glaucoma; this case may be similar to those described by Genet (1936), Smith (1955), and Dobree (1957), who noted an increased incidence of retinal venous occlusion in cases with pre-existent glaucoma. The incidence of glaucoma in the present series $(23 \%)$ is less than that reported in most studies of central vein occlusion (Braendstrup, 1950 (47\%); Duff et al., 1951 (43\%); Cassady, 1953 (16\%); Law, 1957 $(28 \%)$; Vannas and Tarkkanen, $1960(42 \%))$.

From the prognostic point of view the retinopathy usually improved out of proportion to vision. Within six months of the incident the retinal haemorrhages had usually resolved. Exudates remained in a few. In the majority, however, some degree of venous distension persisted.

Eight cases developed well-marked degenerative changes at the macula with marked loss of central vision. The frequency of this complication has been emphasized by Wise (1957). Optic atrophy developed in one case. The extent of the visual loss present at the first visit is shown in Fig. 1. A second measurement of visual acuity was made in 32 patients, after an interval of 6-12 months: in 11 visual acuity had improved, in nine it had remained unchanged, and in 12 it had further deteriorated.

\section{Occlusion of Segmental Retinal Vein}

Occlusion of a segmental retinal vein was present in 50 patients (right eye 26, left eye 22 , bilateral 2). In a further patient (Case 11) a central venous occlusion preceded a segmental occlusion in the opposite eye by two years.

The clinical features were in most respects similar to those occurring in occlusion of the central vein. The onset was equally sudden, the loss of vision possibly less (Fig. 1). The

\begin{tabular}{|c|c|c|c|c|}
\hline & $\begin{array}{c}\text { CENTRAL } \\
\text { VEIN }\end{array}$ & $\begin{array}{c}\text { SEGMENTAL } \\
\text { VEIN }\end{array}$ & $\begin{array}{l}\text { CENTRAL } \\
\text { ARTERY }\end{array}$ & $\begin{array}{c}\text { SEGMENTAL } \\
\text { ARTERY }\end{array}$ \\
\hline $6 / 6$ & $\infty$ & 890000 & $\infty$ & \\
\hline $6 / 9$ & $\infty$ & 00000 & & $\bullet$ \\
\hline $6 / 12$ & $x \quad 00000$ & 800000 & & $\bullet \bullet$ \\
\hline $6 / 18$ & $\infty$ & $\infty$ & - & $\bullet$ \\
\hline $6 / 24$ & $\times \quad \infty$ & $\infty$ & & $\bullet$ \\
\hline $6 / 36$ & $x \times \infty$ & $\infty 000$ & & $\infty$ \\
\hline $6 / 60$ & $\times \times 800000$ & 29000 & $\infty$ & $\infty$ \\
\hline C.F. & xx & 000000 & $\bullet$ & $\bullet$ \\
\hline H.M. & $\begin{array}{l}x \times \\
x \times \\
\end{array}$ & & $\infty$ & $\bullet$ \\
\hline P. L. & & & 00000 & \\
\hline N.P.L. & $x$ & & $\bullet$ & \\
\hline
\end{tabular}

$x$ Cases with central vein occlusion and glaucoma

FIG. 1.-Comparison of visual loss in four types of retinal vascular occlusion. Two patients with occlusion of a segmental vein and two patients with occlusion of the central artery are not included.

site of the occlusion was usually in the temporal branches of the retinal vein, often at an arteriovenous crossing. The appearance was of localized venous distension peripheral to the occlusion, associated with extensive haemorrhages in the segment drained by the vein.

Three cases developed glaucoma, four macular degeneration, and one optic atrophy. These findings are comparable to Jensen's (1936) detailed analysis of 54 cases.

\section{Occlusion of Central Retinal Artery}

Occlusion of the central retinal artery was present in 26 patients (right eye 12, left eye 14). In none were both eyes affected. One patient (Case 6) had had an earlier retinal vascular occlusion in the same eye. All cases presented with an acute loss of vision, the extent of which was more marked than in other types of occlusion (Fig. 1). Few cases were seen in the medical clinic within the first week of the occlusion. The appearance of the fundus at this first visit varied. In a minority no retinal lesion was apparent despite the marked visual loss and the subsequent development of change in the optic disk. In the majority of patients, however, retinal oedema, disk swelling, narrowing of the arteries, and pallor of the fundus were present. In a few cases retinal haemorrhages developed. The possibility that these may be attributable to associated venous occlusion is discussed below. As in other forms of occlusion the fundal appearance improved considerably, although the gross visual loss remained unchanged. Valvular heart disease was present in the two cases without visual loss (Fig. 1). It is possible that the occlusion in these patients was embolic. Some degree of optic atrophy developed in most patients. 


\section{Occlusion of Segmental Retinal Artery}

Fourteen cases with segmental artery occlusion were seen ( 7 left-sided, 7 right-sided). The clinical features were similar to those occurring in occlusion of the central artery. The onset was as sudden, the visual loss less (Fig. 1), unless the macula was involved. The appearance was of a narrowed artery with haemorrhages and later exudates in the segment distal to the occlusion.

In only one case was an embolus seen in a retinal artery. This was composed of glistening white material which had become impacted at an arterial bifurcation. A similar appearance has been noted during attacks of transient blindness by Fisher (1959), Hollenhorst (1961), Russell (1961, 1963), McBrien, Bradley, and Ashton (1963), David, Klintworth, Friedberg, and Dillon (1963), and earlier by others. The more recent studies have usually been able to demonstrate carotid artery disease as a potential source for these emboli. In some instances the emboli have been shown to consist of platelet thrombi, in others cholesterol. David et al. (1963) consider the more shining variety to be cholesterol.

It is difficult to determine the frequency with which such emboli cause occlusion of a retinal artery. In both the present series and that of Liversedge and Smith (1962) only one case was seen. A potential source for emboli, carotid atheroma, is known to be common in old people (Hutchinson and Yates, 1957): the time during which emboli can be seen in the retinal circulation is short. It is therefore possible that the present figure is an underestimate of the frequency with which retinal arterial occlusion is due to such emboli.

\section{Medical Aspects of Retinal Vascular Occlusion}

The 146 cases of vascular occlusion are considered together as a group. The data are, however, analysed separately for each type of occlusion. Where differences are apparent, they are indicated.

\section{Age and Sex}

Table II shows the distribution of cases in respect of age and sex. Both sexes were affected equally (male 74, female 72). Generally the women were older than the men. This distribution is in part due to the larger number of women at risk in an elderly population. The pattern of age distribution was similar in the four types of occlusion.

TABLE II.-Distribution of Cases with Retinal Vascular Occlusion by Age and Sex

\begin{tabular}{|c|c|c|c|c|c|c|c|}
\hline Age in years: & $20-29$ & $30-39$ & $40-49$ & $50-59$ & $60-69$ & $70-79$ & $80+$ \\
\hline $\begin{array}{l}\text { Males } \\
\text { Females }\end{array}$ & 1 & $\begin{array}{l}2 \\
2\end{array}$ & $\begin{array}{l}9 \\
4\end{array}$ & $\begin{array}{l}23 \\
12\end{array}$ & $\begin{array}{l}27 \\
34\end{array}$ & $\begin{array}{l}10 \\
17\end{array}$ & $\begin{array}{l}2 \\
3\end{array}$ \\
\hline
\end{tabular}

\section{Blood-pressure}

In most series of retinal vascular occlusion where bloodpressure has been recorded the majority of cases had either a normal or slightly raised blood-pressure, a minority had severe hypertension. This distribution is also apparent in the present series (Table III). The retinal vascular occlusion group has been compared with the matched control group described in the

TABLE III.-Distribution of Diastolic Blood-pressure in Retinal Vascular

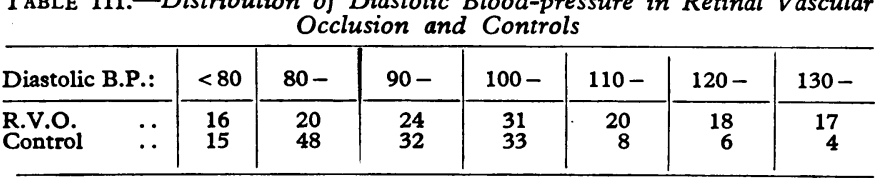

section on methods. This control group has a similar distribution of blood-pressure to that of the normal population studied by Hamilton, Pickering, Roberts, and Sowry (1954). A marked difference is apparent between the control groups on the one hand and the retinal vascular group on the other.

This association between high blood-pressure and retinal vascular occlusion might be related to the increased incidence of other forms of occlusive vascular disease occurring in hypertensive patients (Pickering, 1955).

The presence of malignant hypertension did not seem an important factor, as in only two cases were the changes of malignant hypertension present in the other eye.

Although a relation between high blood-pressure and retinal vascular occlusion is apparent in this and other series, only 55 patients $(38 \%$ ) had a diastolic blood-pressure of $110 \mathrm{~mm} . \mathrm{Hg}$ or more when first seen.

\section{Vascular Disease in Other Sites}

Twenty-one patients in the present series gave either a clear history of angina pectoris or had at some time had a myocardial infarct proved by electrocardiogram. Intermittent claudication was present in eight of the series. Four of these patients had histories of both angina and intermittent claudication.

A history of such ischaemic disease was more often encountered in patients with retinal venous obstruction (22 of 106 patients) than in those in whom the obstruction was arterial ( 3 of 40 patients). The difference in frequency is of borderline significance $\left(\chi^{2}=2.72, \mathrm{P}=0.1-0.05\right)$.

Evidence of cerebrovascular disease was present in seven patients: three had a hemiplegia, three had both a hemiplegia and either clinical or radiological evidence of carotid artery stenosis, and one had carotid artery stenosis without hemiplegia. The retinal vascular occlusion in the four cases with evidence of carotid disease was arterial in three and venous in one. The possibility that emboli might cause such arterial occlusion has been discussed.

\section{Disease Associated with Vasculitis}

Temporal Arteritis.-Four patients had temporal arteritis: in three the occlusion was arterial and in one venous. Ophthalmic complications, including vascular occlusion, are known to be common in this condition (Parsons-Smith, 1959; Whitfield, Bateman, and Cooke, 1963).

Disseminated Lupus Erythematosus.-This was present in one case with occlusion of a central retinal vein.

Ankylosing Spondylitis and Rheumatoid Arthritis.-One case each of ankylosing spondylitis and rheumatoid arthritis occurred in the present series. Both were present in patients with retinal venous occlusion. While a periphlebitis is known to occur in rheumatoid arthritis (Kulka, 1959) and vasculitis in ankylosing spondylitis (Graham and Smythe, 1958), the association in these cases could well be coincidental.

\section{Valvular Heart Disease}

Five patients had some form of valvular heart disease: two with mitral incompetence, two with aortic stenosis, and one with mitral stenosis. In the patient with mitral stenosis the occlusion was venous, in the remainder arterial.

Retinal arterial occlusion is known to be associated with valvular heart disease, but it is not common in any series of cases with retinal vascular occlusion. Moreover, in a group of 194 patients with rheumatic heart disease complicated by systemic embolism only three had retinal emboli (Daley, Mattingly, Holt, Bland, and White, 1951). 


\section{Diabetes}

It is recognized that the definition of diabetes is very difficult, but an abnormal glucose-tolerance test of diabetic type (see above) was present in 16 of the 146 cases with retinal vascular occlusion (14 out of 106 with venous occlusion and 2 out of 40 with arterial occlusion). The incidence of diabetes might well be higher, as glucose-tolerance tests were performed in only 23 cases. In only five of the 16 diabetics was glycosuria present at the initial urine test, the diagnosis in the remainder being suggested by the fundal appearance. The incidence of diabetes in this group is at present being determined by a glucosetolerance test in each patient.

Butterfield (1964) and Keen (1964) have emphasized the extent to which the apparent incidence of diabetes can vary with the method of detection. As part of a survey of diabetes in the general population, glucose-tolerance tests were performed in 570 randomly selected subjects without glycosuria. Of these, 90 were found to be abnormal. The incidence of vascular disease in this group of diabetics without glycosuria was significantly higher than in the non-diabetics.

Generally the diabetes in the present cases was mild and readily controlled by diet or chlorpropamide. In no patient was insulin required. In the majority the presence of diabetes was unknown at the time of the retinal vascular occlusion.

Retinopathy in diabetes is well known, as is the tendency of diabetics to develop vascular occlusion in other sites. Occlusion of a major retinal vessel is not a frequently recognized complication of overt diabetes. It is not reported in large series followed by Lundbaek and Jensen (1953) and Lister (1959). It is not, however, unknown (Braendstrup, 1950 ; Mancall, 1951; Warren and LeCompte, 1952 ; Cassady, 1953 ; Lister and Zwink, 1953 ; Morgan, 1955 ; Hecker and Zweng, 1961).

The similarity between diabetic retinopathy and retinal venous occlusion has been stressed (Ballantyne and Michaelson, 1947 ; Becker and Post, 1951 ; Wise, 1957). Both conditions are associated with retinal haemorrhages, microaneurysms, new vessel formation, rubeosis iridis, and glaucoma. Ditzel and Sagild (1954) consider that the main vascular lesion in diabetes is on the venous side of the circulation (see discussion by Ashton, 1963).

\section{Neoplastic Conditions}

Some form of neoplasm was present in 13 of the 146 patients seen. In four a carcinoma had been excised in the three-year period before the retinal vascular occlusion. In the remaining nine patients the neoplasm presented after the retinal lesion. One of these (Case 2) had two separate carcinomas, each associated in time with a separate retinal vascular occlusion.

A brief description of the cases with neoplasm and retinal vascular occlusion is given.

Case 1.-A woman of 60 had a hemicolectomy in 1960 for carcinoma of the colon. The diagnosis was confirmed histologically. In 1962 she developed occlusion of a central retinal artery. She has been followed since that time, without sign of recurrent carcinoma.

Case 2.-A woman of 69 was blinded in the right eye in 1955 by a retinal vascular occlusion. In 1958 a large carcinoma of the caecum was removed, the diagnosis being confirmed histologically. In 1963 she developed occlusion of a central retinal vein in the left eye. Investigation revealed a carcinoma of the left colon, which was subsequently resected, the diagnosis again being confirmed histologically.

Case 3.-A woman of 76 presented in 1961 with occlusion of a segmental retinal vein. On examination she was found to have an abdominal mass which on barium-meal examination was thought to be a carcinoma of the stomach. She died later that year. The diagnosis was confirmed at necropsy.

Case 4.-A man of 66 had occlusion of a segmental retinal artery in 1959. This was followed by macular degeneration. In 1961 a peripheral carcinoma of the lung was diagnosed and treated by radiotherapy. He died in 1962 with carcinomatosis.

Case 5.-A man of 50 developed an occlusion of the central retinal artery in 1962. In 1963, after an episode of thrombophlebitis, a carcinoma of the bronchus was confirmed at bronchoscopy.

Case 6.-A man of 65 , with a past history of tuberculosis, inactive at the time of his first retinal vascular occlusion in 1958, was blinded in the same eye in 1962 by occlusion of a central retinal artery. A lesion was apparent on $x$-ray examination of the chest at this time. This was subsequently shown to be a carcinoma of the bronchus, from which he died in 1963.

Case 7.-A man of 74 was under treatment at another hospital for carcinoma of the prostate at the time of his central retinal venous occlusion in 1961. The diagnosis in this case was supported by a raised acid phosphatase.

Case 8.-A woman of 67 had an occlusion of the central retinal vein in July 1963 . Although her breasts were noted to be normal at this time, a mass was discovered in October 1963 which, on radical mastectomy a month later, was shown to be carcinoma.

Case 9.-A woman of 64 had had a mastectomy for a histologically proved carcinoma three years before occlusion of a segmental retinal vein. In the year following the occlusion there were no signs of recurrence.

Case 10.-A woman of 62 had had a mastectomy for a proved carcinoma two years before occlusion of a segmental retinal artery. Similarly, in this case there were no signs of recurrence.

Case 11.-A woman of 78 developed occlusion of a right central vein in 1958. Two years later occlusion of a segmental vein occurred in the other eye. On examination she was found to have a large carcinoma of the breast. This was excised, the diagnosis being confirmed histologically. She has since remained well.

Case 12.-A woman of 67 had a hysterectomy and radiotherapy for invasive carcinoma of the cervix in 1961. Seven months later occlusion of a central retinal vein occurred, since when she has remained well.

Case 13.-A man of 77 presented in 1962 with occlusion of a central vein. Investigation revealed the presence of multiple myeloma. (This case has not been included in the calculations relating to carcinoma.)

The frequency with which neoplasms occur in the present series raises the possibility of their association with retinal vascular occlusion. A precedent for this would certainly exist in the association of thrombophlebitis migrans and visceral carcinoma first described by Trousseau in 1877. Since that time other forms of thrombosis affecting deep veins, arteries, and even cardiac valves have been reported in association with primary carcinomas of the stomach, bronchus, gall-bladder, ovary, and prostate (Osler and McCrae, 1900 ; Sproul, 1938 ; Fisher, Hochberg, and Wilensky, 1951 ; Mirabel, 1954; Williams, 1954 ; Bell, 1957). Mirabel (1954) records a case associated with a reticulosarcoma.

Most of these reports emphasize the frequency with which the thrombosis precedes the clinical manifestation of the neoplasm. Intervals of a year or more were common. A similar relation was apparent in Cases $2,4,5,6,8$, and 11 of the present series. Also emphasized in these reports was the tendency to multiple thrombosis. In the present series recurrent retinal vascular occlusion was rare (7 out of 146 cases). Of these, however, three were associated with carcinoma (Cases 2, 6 , and 11). One further patient (Case 5) had a superficial thrombophlebitis in addition to the retinal lesion.

In most of these cases the occlusion was venous. In the three cases with carcinoma of the bronchus, however, the occlusion was arterial. As arterial emboli have been reported in carcinoma of the bronchus (Greenberg, Divertie, and Woolner, 1964, review) it is possible that the occlusion in the present cases was embolic.

Other studies of retinal vascular occlusion do not emphasize a relation between occlusion of the retinal vessels and carcinoma. Few of these, however, report a medical follow up or the causes of death within the series. Exceptions are the papers of Jensen (1936) and Liversedge and Smith (1962), who report a total 
of 16 deaths. Of these, six were due to carcinoma and one to leukaemia.

Twelve cases of carcinoma were diagnosed in the present series. In the matched control group described in the section on methods three cases were diagnosed. While the difference in incidence of carcinoma in the two groups is significant $\left(\chi^{2}=4.50\right.$, $P=0.02-0.05$ ), it is emphasized that the study was retrospective and the numbers involved were small.

\section{Other Conditions}

Several other conditions were encountered in the present series of patients. It is unlikely that they are related to retinal vascular occlusion. They included peptic ulcer (three cases), gall-stone (two cases), psoriasis (two cases), and one case each of renal calculi, thrombophlebitis, myxoedema, tuberculosis, and hiatus hernia.

Four patients had a haemoglobin of less than $70 \%$. In two the anaemia was iron deficiency in type and probably attributable to gastro-intestinal bleeding; in two patients (Cases 2 and 6) a carcinoma was present.

\section{Smoking}

During 1963 details of the smoking habits of 133 of the 146 patients with retinal vascular occlusion were obtained. These have been compared with the control groups described in the section on methods.

Retinal Venous Occlusion.-The smoking habits of 97 patients with retinal venous occlusion have been compared with 97 matched control patients (Fig. 2). Although the number of patients who were smokers at the time of their venous occlusion (50-51\% of group) was slightly higher than the number in the control series (39-40\% of group), the difference is not significant $\left(\chi^{2}=2.08, \mathrm{P}>0.2\right)$.

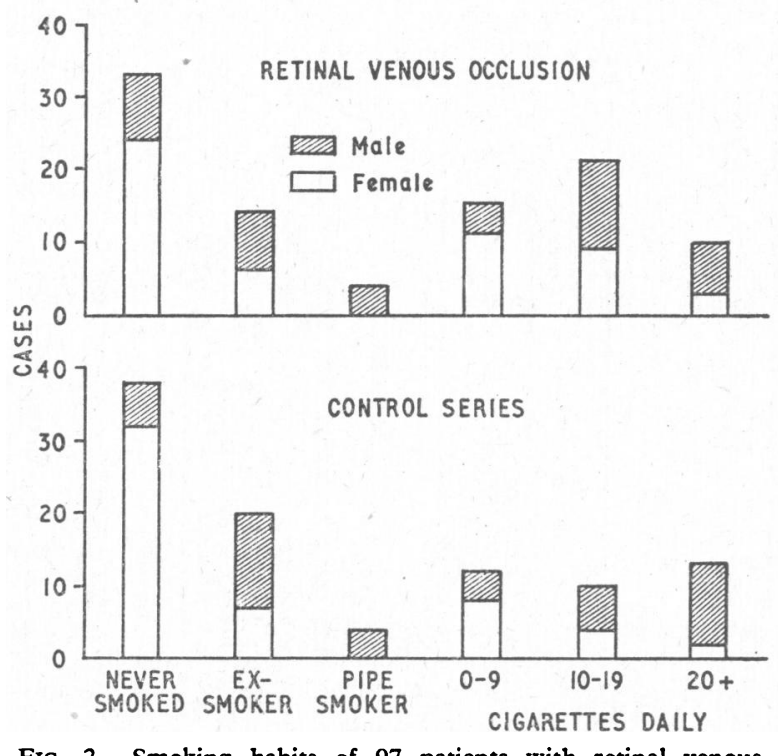

FIG. 2.-Smoking habits of 97 patients with retinal venous occlusion compared with those of matched controls.

Retinal Artery Occlusion.-A similar comparison has been made between 28 patients with occlusion of a retinal artery and a control population (Fig. 3). In contrast to the patients with venous occlusion all the men and most of the women were smokers. The number of smokers within this group (24, 86\% of group) is significantly higher $\left(x^{2}=10.97, \mathrm{P}<0.01\right)$ than the number in the control group (11,39\% of group).

Cases Excluded from Comparison.-Thirteen patients (nine venous occlusion, four arterial) from whom a smoking history could not be obtained and eight cases with arterial occlusion were excluded. The latter eight were patients with temporal arteritis, valvular heart disease, or carotid artery stenosis ; their smoking habits did not differ markedly from the control group (Fig. 3).

Validity of the Matching.-Details of the matching technique have been described earlier. The histories of smoking habits were taken retrospectively and may therefore have been biased. It is unlikely, however, that the differences observed could be attributed to bias of this kind, as it was not appreciated until a later stage that the apparent association with smoking was confined to the group of cases with occlusion of the retinal artery. For the same reason it is less likely that the difference observed is attributable to inappropriate matching of groups.
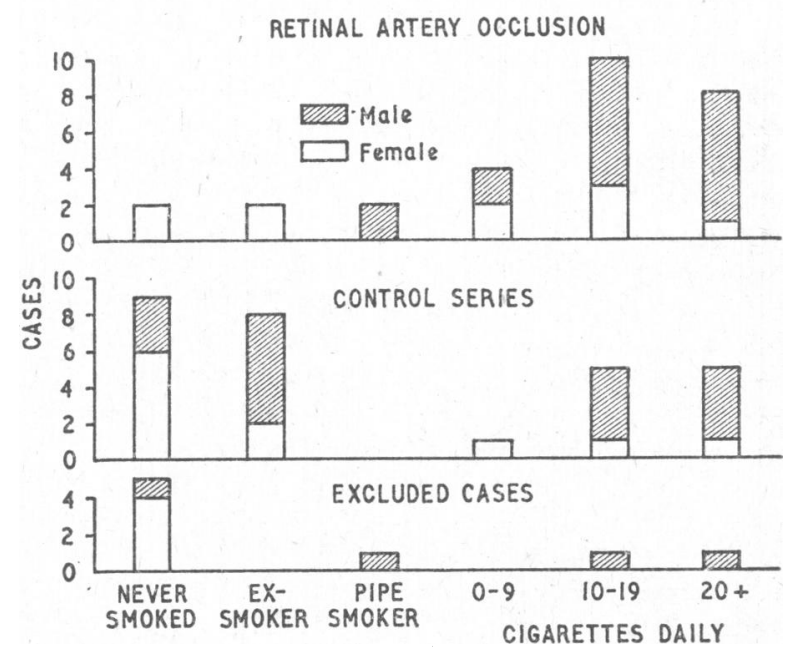

FIG. 3.-Smoking habits of 28 patients with retinal artery occlusion compared with those of matched controls.

Both of the control groups were drawn at random from the same population; the difference observed, however, is confined to a comparison with one of these groups.

Smoking is known to be related to other forms of arterial disease. Doll and Hill (1956), Hammond and Horn (1958), and others have demonstrated an increased mortality from ischaemic heart disease among cigarette smokers. Cigarette smoking is thought to be a major cause of thromboangiitis obliterans (for references see Larson, Haag, and Silvette, 1961). Fink (1946) has shown that smoking a single cigarette produces a marked increase in the size of the normal angioscotoma. The duration of the effect was one hour. More extensive changes occurred when patients with glaucoma smoked cigarettes (Castagno, 1950). The mechanism of this effect was thought to be vascular.

These demonstrations of an effect of smoking on the vascular system of the eye, together with the results in the present series, raise the question of a relation between smoking and occlusion of the retinal artery. The limitations of the present retrospective survey are recognized. To establish a definite relation a larger number of cases studied in a prospective survey would be required.

\section{Discussion}

In the present series $56 \%$ of the patients had at least one medical condition in addition to their retinal vascular occlusion. These included a diastolic blood-pressure of $120 \mathrm{~mm}$. $\mathrm{Hg}$ or more, ischaemic heart disease, intermittent claudication, carotid artery stenosis, valvular heart disease, temporal arteritis, disseminated lupus erythematosus, diabetes, and carcinoma. In most cases the presence of this condition was not known at the time of the retinal vascular occlusion. For this reason it would seem justifiable that all cases of retinal vascular occlusion should be investigated jointly in ophthalmic and medical clinics. 
The frequency with which some conditions occur in the present series raises the possibility of their association with retinal vascular occlusion. The occurrence of a few cases of temporal arteritis, carotid artery stenosis, disseminated lupus erythematosus, and valvular heart disease would be expected on the basis of the well-known association of these conditions with retinal vascular occlusion. These cases are, however, a small minority and comprise less than $10 \%$ of the whole group. The possibility of an association between carcinoma and retinal vascular occlusion has been discussed. A larger number of patients had hypertension, diabetes, angina, cardiac infarction, or intermittent claudication. Hypertension was found with equal frequency in patients with venous and arterial obstruction. The ischaemic diseases were encountered more often in patients with retinal venous occlusion.

Retinal Artery Occlusion.-This was associated with cigarette smoking and with hypertension as has been stated (cigarette smoking was unrelated to hypertension). A small proportion of cases had either valvular heart disease or carotid artery stenosis. The possibility of embolic occlusion in these has been considered. Temporal arteritis was present in three cases.

Retinal Venous Occlusion.-The pathogenesis of retinal venous occlusion has been debated since von Michel's (1878) original description. Most consider it likely that several factors are involved (Bearman, 1962). That external compression of the vein might be one is indicated by the development of central vein thrombosis in cases with glaucoma, and the frequency with which segmental vein occlusion occurs at an $\mathrm{A} / \mathrm{V}$ crossing. That a defect of blood coagulation might be involved in some cases is suggested by the association of retinal venous occlusion with polycythaemia and myeloma (Wintrobe and Buell, 1933 ; Anderson and Vallotton, 1955). The possibility that retinal venous occlusion might be related to diabetes is at present under investigation. A further possibility discussed by Braendstrup (1950) is that retinal arterial disease could itself produce a venous thrombosis. Several series report episodes in which occlusion of an artery is followed by occlusion of a vein. The frequency with which such a sequence occurs is likely to be underestimated, as the florid changes of venous obstruction would obscure the less marked features of an earlier arterial lesion. In the present study cases of venous occlusion occurred in confirmed carotid artery stenosis, temporal arteritis, disseminated lupus erythematosus, mitral stenosis, and malignant hypertension-conditions which in other respects are associated with arterial lesions.

\section{Summary}

The medical investigation of 146 cases of retinal vascular occlusion is described.

In 40 cases the obstruction was arterial, in 106 venous. The ophthalmic features of these cases were similar in most respects to those reported in other series.

In $56 \%$ of the cases, at least one important medical condition was present in addition to the retinal vascular occlusion. These included severe hypertension, ischaemic disease in sites other than the eye, temporal arteritis, valvular heart disease, diabetes, and carcinoma. The possibility that some of these conditions might be associated with retinal vascular occlusion is discussed.

The number of smokers in a group of patients with occlusion of a retinal artery was significantly higher than the number in a matched control group.

We would like to thank our medical and nursing colleagues at the Western Ophthalmic Hospital for their co-operation in this survey.
Mr. R. A. Burn, Mr. R. K. Blach, Dr. Harry Keen, and Dr. G. A. Rose gave special advice, for which we are grateful.

\section{REFERENCES}

Anderson, B., and Vallotton, W. (1955). Arch. Ophthal., 54, 6.

Ashton, N. (1963). Brit. 7. Ophthal., 47, 521.

Ballantyne, A. J., and Michaelson, I. C. (1947). Trans. ophthal. Soc. U.K., 67, 59.

Becker, B., and Post, L T. (1951). Amer. F. Ophthal., 34, 677.

Behrman, S. (1962). Brit. F. Ophthal., 46, 336.

Bell, E. T. (1957). Amer. f. Path., 33, 499.

Braendstrup, P. (1950). Acta ophthal. (Kbh.), Suppl. No. 35.

Butterfield, W. J. H. (1964). Proc. roy. Soc. Med., 57, 196.

Cassady, J. V. (1953). Amer. f. Ophthal., 36, 331

Castagno, M. M. (1950). Ibid., 33, 1431.

Daley, R., Mattingly, T. W., Holt, C. L., Bland, E. F., and White, P. D. (1951). Amer. Heart f., 42, 566.

David, N. J., Klintworth, G. K., Friedberg, S. J., and Dillon, M. (1963). Neurology (Minneap.), 13, 708.

Ditzel, J., and Sagild, U. (1954). New Engl. f. Med., 250, 587.

Dobree, J. H. (1957). Trans. ophthal. Soc. U.K., 77, 229.

Doll, R., and Hill, A. B. (1956). Brit. med. F., 2, 1071.

Duff, I. F., Falls, H. F., and Linman, J. W. (1951). Arch. Ophthal., 46, 601.

Fink, A. I. (1946). Ibid., 35, 15.

Fisher, C. M. (1959). Neurology (Minneap.), 9, 333.

Fisher, M. M., Hochberg, L. A., and Wilensky, N. D. (1951). F. Amer. med. Ass., 147, 1213.

Genet, M. L. (1936). Bull. Soc. Ophtal. Paris, 48, 831.

Graham, D. C., and Smythe, H. A. (1958). Bull. rheum. Dis., 9, 171.

Greenberg, E., Divertie, M. B., and Woolner, L. B. (1964). Amer. 7. Med., 36, 106.

Hamilton, M., Pickering, G. W., Roberts, J. A. F., and Sowry, G. S. C. (1954). Clin. Sci., 13, 11.

Hammond, E. C., and Horn, D. (1958). F. Amer. med. Ass., 166, 1159, 1294.

Hecker, S. P., and Zweng, H. C. (1961). Ibid., 176, 1067.

Hollenhorst, R. W. (1961). Trans. Amer. ophthal. Soc., 59, 252.

Hutchinson, E. C., and Yates, P. O. (1957). Lancet, 1, 2.

Jensen, V. A. (1936). Acta ophthal. (Kbh.), Suppl. No. 10, p. 1.

Keen, H. (1964). Proc. roy. Soc. Med., 57, 200.

Klien, B. A. (1953). Amer. F. Ophthal., 36, 316.

Kulka, J. P. (1959). f. chron. Dis., 10, 388.

Larson, P. S., Haag, H. B., and Silvette, H. (1961). Tobacco, Experimental and Clinical Studies. Williams and Wilkins, Baltimore.

Law, F. W. (1957). Trans. Canad. ophthal. Soc., 9, 38.

Lister, A., and Zwink, F. B. (1953). Trans. ophthal. Soc. U.K., 73, 55.

Lister, J. (1959). The Clinical Syndrome of Diabetes Mellitus. Lewis, London.

Liversedge, L. A., and Smith, V. H. (1962). Trans, ophthal. Soc. U.K., 82, 571 .

Lundbaek, K., and Jensen, V. A. (1953). Long Term Diabetes. Munksgaard, Copenhagen.

McBrien, D. J., Bradley, R. D., and Ashton, N. (1963). Lancet, 1, 697.

Mancall, I. T. (1951). Arch. Ophthal., 46, 668.

Mirabel, L. (1954). Canad. med. Ass. 7., 70, 34.

Morgan, O. G. (1955). Trans. ophthal Soc. U.K., 75, 3

Osler, W., and McCrae, T. (1900). Philad. med. F., 5, 245.

Parsons-Smith, G. (1959). Brit. F. Ophthal., 43, 204.

Pickering, G. W. (1955). High Blood Pressure. Churchill, London.

Russell, R. W. R. (1961). Lancet, 2, 1422.

- (1963). Ibid., 2, 1354.

Smith, R. (1955). Trans. ophthal. Soc. U.K., 75, 265.

Sproul, E. E. (1938). Amer. F. Cancer, 34, 566.

Stephenson, R. W. (1956). Trans. ophthal. Soc. U.K., 76, 253.

Thorne, B. T. (1961). Proc. roy. Soc. Med., 54, 856.

Tiburtius, H. (1960). Klin. Mbl. Augenheilk., 136, 604.

Trousseau, A. (1877). Clinique Médicale de l'Hôtel-Dieu de Paris, 5th ed., 3, 94. Baillière, Paris.

Vannas, S., and Tarkkanen, A. (1960). Brit. 7. Ophthal., 44, 583.

von Michel, J. (1878). Arch. Ophthal. (Berl.), 24, 131.

Warren, S., and LeCompte, P. M. (1952). The Pathology of Diabetes Mellitus, p. 189. Kimpton, London.

Whitfield, A. G. W., Bateman, M., and Cooke, W. T. (1963). Brit. f. Ophthal., 47, 555 .

Williams, A. A. (1954). Brit. med. F., 2, 82.

Wintrobe, M. M., and Buell, M. V. (1933). Bull. Fohns Hopk. Hosp., $52,156$.

Wise, G. N. (1957). Arch. Ophthal., 58, 544. 